\title{
Selective breeding of Arabian and Thoroughbred racehorses in Algeria: perceptions, objectives and practices of owners-breeders
}

\author{
Safia Tennah ${ }^{1,2}$, Frédéric Farnir ${ }^{1}$, Nacerredine Kafidi ${ }^{2,4}$, Ibrahim Njikam Nsangou ${ }^{1}$, \\ Pascal Leroy ${ }^{1,3}$, Nicolas Antoine-Moussiaux ${ }^{1,3}$
}

\author{
${ }^{1}$ Department of Animal Production, Unit of Genetics, Biostatistics and Rural Economics, Faculty of Veterinary Medicine, University of Liege, \\ Liege, Belgium. \\ ${ }^{2}$ School Veterinary National Superior of Algiers, Algiers, Algeria. \\ ${ }^{3}$ Tropical Veterinary Institute, Faculty of Veterinary Medicine, University of Liege, Liege, Belgium \\ ${ }^{4}$ Canadian Food Inspection Agency, Ottawa, Canada.
}

\begin{abstract}
This survey, conducted with 461 racehorse owners-breeders in Algeria between 2009 and 2011, investigates their perceptions, objectives and practices regarding selective breeding. Racehorse breeding is a full-time professional activity for a third of interviewees. The holdings are small-sized with $77 \%$ owning one or two mares. The regular practice of mating is here used to categorize breeders according to their degree of professionalization (38.4\% professional vs. $61.6 \%$ occasional breeders). Experience in the sector was also used to classify breeders, considering as "junior" the breeders under 10 years experience (38.8\%) and as "senior" those above 10 years (61.2\%). More than professionalization, experience shows a significant impact on practices and objectives. Thus, experience influences breed choice (junior breeders tend to specialize while senior own both Arabian and Thoroughbreds), age at first foaling (sooner among senior breeders), information sources considered for selecting stallions (senior use more diversified sources), the importance granted to the price of mating (greater for junior breeders), the importance granted to the ranking compared to earnings (the ranking being more important to junior breeders), and the priority given to breeding (junior breeders give higher priority to a buy-race-resell activity). Finally, racehorse breeding is poorly professionalized, the only financial goal being cost coverage. Despite inappropriate practices, an interest for selection is noticed.
\end{abstract}

Key Words: animal-breeding, flat racing, horses, horse breeder, selection, survey

\section{Introduction}

In Algeria, horse-breeding has a high economic and socio-cultural importance. Many farms still use horses for agricultural work and the transportation of goods and people. In urban areas, the horse is also used in equine sporting and leisure. Algeria is the African country with the largest equine population, with nearly 240,000 animals (OIE, 2010). The Algerian equine population underwent a drop between 1993 and 2001 but was then stabilized (FAOSTAT, 2012).

This equine population is mainly composed of three breeds: the Arabian horse (Ar), the Barb and the Thoroughbred (En). A large part of the population is made up of crossbreds, mainly "Arabian-Barb" (Benabdelmoumene, 2003; Kadri, 2006). The distribution of breeds within the equine population is as follows: $10 \% \mathrm{En}, 13 \% \mathrm{Ar}, 16 \%$

Received February 21, 2013 and accepted November 21, 2013.

Corresponding author: nantoine@ulg.ac.be

http://dx.doi.org/10.1590/S1516-35982014000400005

Copyright $@ 2014$ Sociedade Brasileira de Zootecnia. This is an Open Access article distributed under the terms of the Creative Commons Attribution Non-Commercial License, which permits unrestricted non-commercial use, distribution, and reproduction in any medium, provided the original work is properly cited.
Barb, 53\% Arabian-Barb and 8\% other than thoroughbred (OTTB). This population is spread across the Algerian territory with $34 \%$ in the West of the country, $25 \%$ in the Center, $22 \%$ in the East and $19 \%$ in the South (MADR, 2009). Although Ar and En horses have been used in Algeria since the early 20 th century for flat racing $(90 \%)$ and trotting $(10 \%)$, no assessment of their genetic potential has been undertaken. Genetic improvement is fundamental to all livestock sectors. Because it is characterized by positive externalities and the need to work on a large scale in order to guarantee efficacy, selective breeding is mostly carried out by large structures organized by private breeders or states. Although the public authorities are equipped with structures dedicated to the equine sector, they do not perform the tasks needed for an effective selection system. Currently, selection is in the hands of owner-breeders, lacking the technical and scientific support necessary for the establishment of a rigorous selection scheme. A good understanding of the practices and motivation of breeders is a pre-requisite to the setting up of any genetic improvement program. In the absence of information relative to these aspects, the present study aims at assessing practices of owner-breeders regarding racehorse selection (Ar and En), 
as well as the perceptions and objectives driving the latter practices.

\section{Material and Methods}

The survey was conducted between January 2009 and August 2011, among 461 owner-breeders of horses (OBH), representing $81 \%$ of those identified by the Algerian horse racing society. The sampling was carried out in situ, on racing days and covered all nine Algerian racetracks (Figure 1). A structured questionnaire was conducted during a one-to-one interview by a single interviewer. The questionnaire included both closed and open-ended questions. Each interview lasted two hours on average. The interviewees freely expressed themselves on the following three subjects.

The criteria dealt with here are experience and experience in the practice of breeding and racing, the number of horses and breeds possessed, the mating frequency of mares and the priority given to racing or reproduction purposes in the management of mares.

The criteria used by $\mathrm{OBH}$ in the choice of animals for breeding were first listed on the basis of the results of a preliminary survey, consisting in the short semi-structured individual interview of $226 \mathrm{OBH}$ encountered on race days at the nine racecourses between January and March 2009. The suggested selection criteria for stallions were conformation, the individual performance, the performance of ascendants, progeny and siblings, the price of mating, the temperament of the stallion and the place where the mating stallion is kept (distance). In addition to these

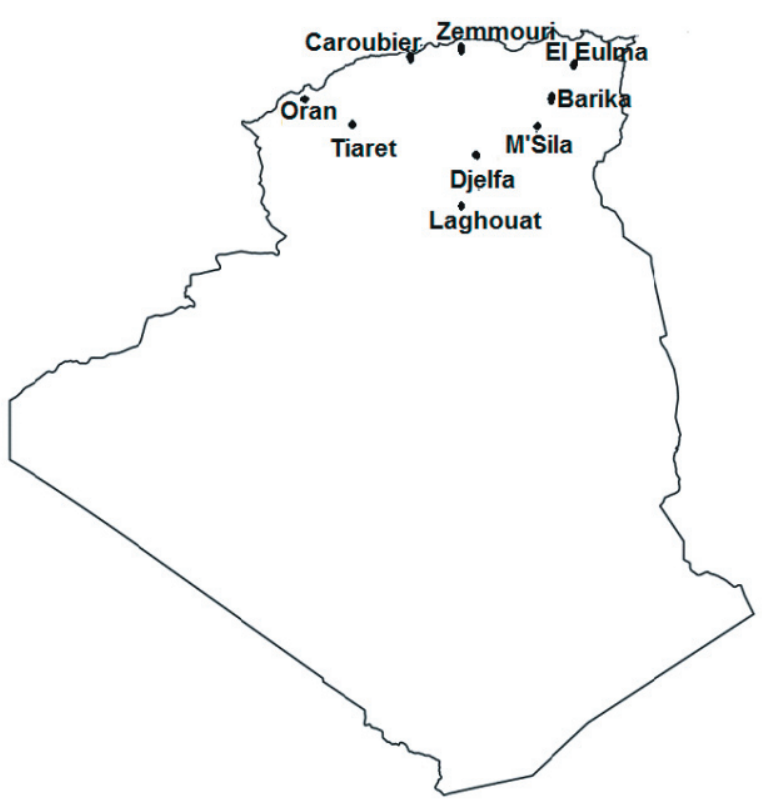

Figure 1 - Location of racetracks across the Algerian territory. selection criteria, the state or private ownership of the stallion appeared as meaningful feature of $\mathrm{OBH}$ practices. The selection criteria for breeding mares were weak racing performance, occurrence of diseases and the bad conformation for racing. Two particular features in $\mathrm{OBH}$ practices were also studied: age at first mating of mares and the possible use of good performing mares for mating.

At the end of the questionnaire, an open question raised the issue of the recommendations of $\mathrm{OBH}$ for the improvement of equine breeding in Algeria. Then, the following elements were systematically dealt with even though they were not spontaneously mentioned in the survey: the interest of the Thoroughbred Owners and Breeders Association in the promotion of breeding, the possible introduction of new reproduction techniques like the artificial mating, the attitude towards the mating of related animals (consanguinity) and the practical organization of races.

A second psychometric-type survey was conducted between July and August 2011, in order to specify the question pertaining to breeding objectives, by raising the question of preference for earnings and rankings. This preference was expressed in the form of a sum of money which the interviewees would be prepared to forego in order to benefit from a first-place ranking instead of a second-place ranking (in other words, what extra sum of money they would be ready to accept in order to forego first place). This notion is here called "ranking value". A sample of $60 \mathrm{OBH}$ among the 177 professionals of the first survey was chosen at random. A visual analogue scale, such as that described by Gold et al. (1996), quoted by Happich et al. (2009), was submitted to the participants who were invited to place a mark for the "rankings value" on a horizontal scale in the form of a $20 \mathrm{~cm}$ straight line (distance L), with an indicated lower limit of 50,000 Algerian Dinars (DA) (654\$), and an indicated upper limit of $250,000 \mathrm{DA}(3,271 \$)$, representing the earnings for second place. These earnings suggested for the two limits represent the observed minimum and maximum earnings attributed to first place on races in Algeria. The lines were not graduated in order to avoid memory and clustering effects (Goebel, 1995 cited by Happich et al., 2009). The distance in centimeters between the upper limit and the mark made by the interviewee (distance 1) was used in order to objectify the perception of the "ranking value". The ranking value (D) thus corresponds to the ratio between the distance measured 1 and the total distance L, multiplied by the difference between the earnings of the upper limit (2nd place) and that of the lower limit (1st place). In order to test possible effects of lower and upper values, the exercise 
was repeated with three different values for the lower limit (50,000DA: 654\$, 100,000DA: 1,308\$ and 200,000DA: $2,617 \$)$.

The $461 \mathrm{OBH}$ were divided into four groups following the number of years of experience with regard to the practice of breeding and racing, as follows: 1 to 5 years, 6 to 10 years, 11 to 20 years and more than 20 years. Hereafter, categories under 10 years of experience are denoted "junior" breeders while categories over 10 years experience are cited as "senior" breeders. To take into account the degree of involvement of the OBH in the activity of breeding, strictly speaking (reproduction), another classification was carried out according to the regular practice of mating of mares. Therefore the interviewees who regularly mated their mares were classed as professional breeders while the others were described as occasional breeders (hereafter, the degree of professionalization).

The effects of the category of experience and the degree of professionalization on the different variables were studied by the Chi-square test and occasionally by Fisher's exact test. The effect of the experience of the 60 $\mathrm{OBH}$ on the "ranking value" D was tested through the Wilcoxon test, comparing medians between junior and senior professionals. The statistical analyses were carried out using the SAS software (Statistical Analysis System, version 8).

\section{Results}

The results are presented according to the experience and professionalization of the $\mathrm{OBH}$. The category of professional breeders included 177 breeders and the category of occasional breeders included 284 breeders from among the 461, representing respectively $38.4 \%$ and $61.6 \%$ of the sample. For the experience categories, the following proportions were noted: $15.8,23,30$ and $31.2 \%$, respectively, for the four categories of 1 to 5 years, 6 to 10 years, 11 to 20 years and more than 20 years.

The racecourse at Zemmouri (International racecourse of Algeria) is the most represented (20.4\%). The racecourses at Djelfa and Laghouat are barely represented (5.6\% and $4.6 \%$ respectively). The experience categories were uniformly represented in the racecourses (Table 1 ; $\mathrm{P}>0.05)$. Of the distribution of the $461 \mathrm{OBH}$ per racecourse in terms of breeds possessed (Ar, En or both) (Table 2), a certain dominance and preference for some breeds appears in accordance with the racecourses $(\mathrm{P}<0.001)$.

The owner-breeders of horses questioned are all men who define themselves as "owners and breeders of racehorses". Their levels of education vary: $41 \%$ have never attended school, 26\% attended school at primary level, 20\% attended school at secondary level and 13\% have attended university. The professional activities are very diverse: manufacturers, managers, farmers, craftsmen, accredited professionals, workers, retirees and some unemployed individuals.

The interviewees declare their involvement in horsebreeding to be a passion and they are the owners of the horses they breed. Half of the OBH $(52 \%)$ state that horse breeding represents part of the family activity, $14 \%$ employ one or several workers and the remainder (34\%) manage the breeding by themselves. They all share the objective of producing high-performance horses. The horses are entrusted to the care of stables by $38 \%$ of the $\mathrm{OBH}$ and are trained by professionals. The remaining $62 \%$ work with their horses at home and consider themselves as breedertrainers. Twenty-one percent of the $\mathrm{OBH}$ are riders. The marketing of good horses, whether they are champions or descended from champions, is a major objective of the activity of horse breeding. For $39 \%$ of the OBH, the purchase and sale of horses is an important part of their activity. For $42 \%$ of the occasional breeders and $8 \%$ of the

Table 1 - Distribution of the owners-breeders between racecourses according to the experience (\%)

\begin{tabular}{|c|c|c|c|c|c|c|}
\hline \multirow{2}{*}{ Racetracks } & \multicolumn{6}{|c|}{ Owners-breeders } \\
\hline & Groups experience & $1-5$ & $6-10$ & $11-20$ & $>20$ & Test \\
\hline BAR & 12.4 & 11.0 & 12.3 & 14.5 & 11.1 & \\
\hline CAR & 7.4 & 6.8 & 4.7 & 7.2 & 9.7 & \\
\hline DJE & 5.6 & 6.8 & 6.6 & 6.5 & 3.5 & \\
\hline EUL & 13.7 & 16.4 & 14.1 & 13.0 & 12.5 & \\
\hline LAG & 4.6 & 6.8 & 4.7 & 3.6 & 4.1 & ns \\
\hline MSI & 7.8 & 6.8 & 8.5 & 8.7 & 6.9 & \\
\hline ORA & 13.0 & 13.7 & 19.8 & 11.6 & 9.0 & \\
\hline TIAR & 15.1 & 9.6 & 13.2 & 17.4 & 17.3 & \\
\hline ZEM & 20.4 & 21.9 & 16.0 & 17.4 & 25.7 & \\
\hline $\mathrm{n}$ & 461 & 73 & 106 & 138 & 144 & \\
\hline
\end{tabular}


professional breeders, horse breeding is a secondary activity. They state that it represents only a small part of their income. For them, horse breeding is a passion to be financed rather than a source of income. For the professional breeders, the activity of breeding is considered to be a difficult and restrictive profession even though it is an exciting and enjoyable activity. For a large majority of professional breeders (83\%), the financial objective is the balance between spending and income and not profit creation. Combination with another form of breeding (essentially cattle and sheep) or another activity is the factor that makes it possible for $57 \%$ of the professional breeders to maintain the activity of horse breeding.

Experience in the activities of breeding and racing varies from 1 to 31 years for the whole sample (median 13 years), from 3 to 31 years for the professional breeders (median 18 years) and from 1 to 30 years for the occasional breeders (median 11 years). Thus experience differs significantly according to the degree of professionalization $(\mathrm{P}<0.001)$.

Forty-six percent of the $\mathrm{OBH}$ are members of the National Association of Breeders and Owners of Thoroughbred Horses (ANEPCRP). However, only the professional breeders, who represent $16 \%$ of the members, are active and regularly attend the debates and meetings organized by the association.

The holdings are mainly small-sized: $77 \%$ of $\mathrm{OBH}$ possess one or two mares (maximum 20), and $81 \%$ one or two males (maximum 10) (Figure 2). The males can be used for racing or as studs, in their own holding or as a service to other breeders. The latter service implies the approval of the stallion by ONDEEC and the National Stud farm. The $\mathrm{OBH}$ can call upon the service supplied by private or public (National Stud farm) to ensure renewal and production of their livestock.

Horse numbers, which are divided into three categories of 1-4, 5-9 and $\geq 10$ horses, are not linked to experience $(\mathrm{P}>0.05)$ (Table 3). However, a significant link appears with the degree of professionalization; the highest numbers (5-9 and $\geq 10)$ are present among the professional breeders
$(\mathrm{P}<0.05)$. The choice of breeds is significantly related to both the degree of professionalization and experience $(\mathrm{P}<0.01)$ (Table 3). The occasional breeders, on the other hand, specialize in one breed unlike the professional breeders, who raise two breeds simultaneously (Table 3$)(\mathrm{P}<0.001)$. The less-experienced category (1-5 years) specializes in one breed while a large number of most experienced breeders ( $>20$ years) raise two breeds conjointly.

Professionalization and experience significantly affect the priority given to racing or reproduction $(\mathrm{P}<0.001)$ (Table 3). The vast majority of professional breeders (97.2\%) consider both racing and breeding as important activities, against $55.3 \%$ of the occasional breeders. The junior breeders prioritize racing, while the senior attribute the same importance to the two activities $(100 \%$ in the case of professional breeders).

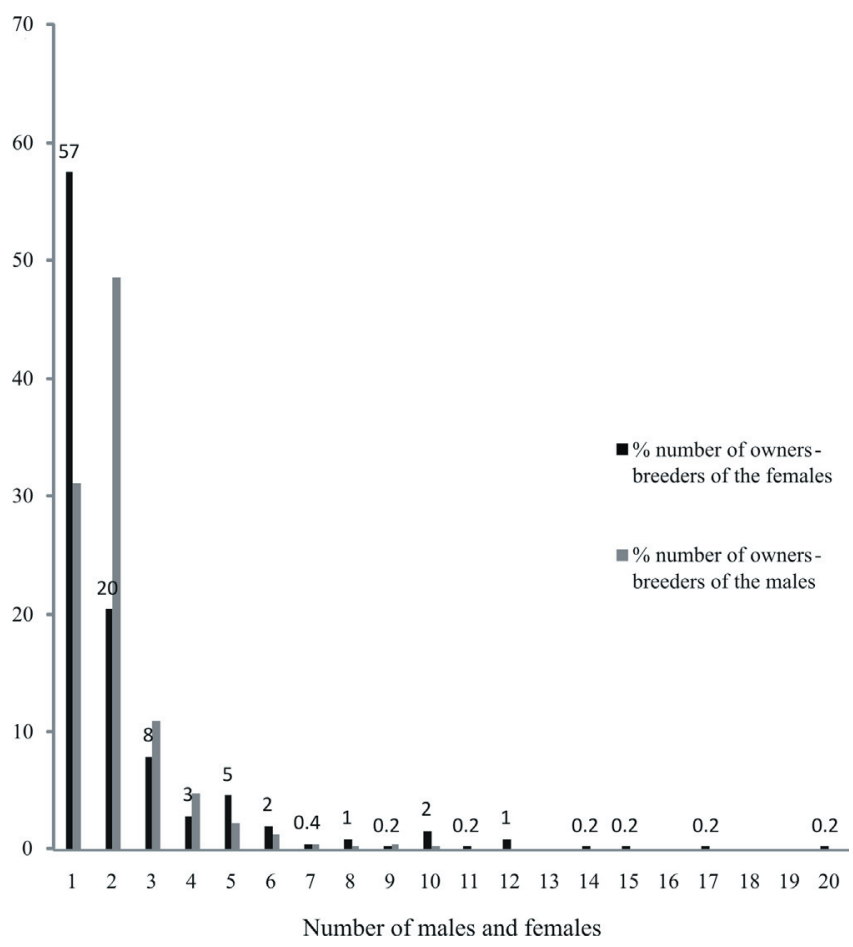

Figure 2 - Distribution of female and male numbers owned by interviewees.

Table 2 - Distribution of the owners-breeders per racecourse in terms of breeds owned (\%)

\begin{tabular}{|c|c|c|c|c|c|c|c|c|c|}
\hline \multirow{2}{*}{ Breeds } & \multicolumn{9}{|c|}{ Racecourse } \\
\hline & BAR & CAR & DJE & EUL & LAG & MSI & ORA & TIAR & ZEM \\
\hline Thoroughbred & 54.4 & 35.3 & 23.0 & 33.3 & 23.8 & 41.7 & 30.0 & 12.9 & 27.7 \\
\hline Arabian horse & 21.0 & 14.7 & 57.7 & 36.5 & 52.4 & 38.9 & 35.0 & 41.4 & 17.0 \\
\hline Both & 24.6 & 50.0 & 19.3 & 30.2 & 23.8 & 19.4 & 35.0 & 45.7 & 55.3 \\
\hline Test & & & & & $* * *$ & & & & \\
\hline
\end{tabular}

$* * * \mathrm{P}<0.001$.

ZEM - Zemmouri (international racecourse); TIAR - Tiaret; ORA - Oran; MSI - Msila; LAG - Laghouat;EUL - Eulma; DJE - Djelfa; CAR - Caroubier; BAR - Barika; Test - Chi ${ }^{2}$. 
Generally, experience and the degree of professionalization do not affect the selection criteria for reproductive mares $(\mathrm{P}>0.05)$ (Table 4$)$. However, the most experienced professional breeders $(>20$ years) are more numerous than the youngest breeders (1-5 years) when it comes to selecting mares for mating as soon as they have reached the age of reproduction $(50 \%$ and $23.9 \%$ respectively) $(\mathrm{P}<0.01)$.

The most cited selection criteria are the weak racing performance $(74 \%$ and $70 \%$ for the professional and occasional breeders, respectively) and the bad conformation of mares for racing (59.9 and $65.5 \%$ for professional and occasional breeders, respectively). Finally, only $35.6 \%$ of professional breeders and $29.9 \%$ of occasional breeders withdraw mares from racing to use them in breeding if they still display good performance (Table 4).

The professional $\mathrm{OBH}$ rely more on the criterion of conformation than the occasional breeders (93.8 and $77.5 \%$ respectively) $(\mathrm{P}<0.001)$. However, this criterion is only significantly linked to experience among the occasional $\mathrm{OBH} \quad(\mathrm{P}<0.001)$. Conformation appears to be more often taken into account by the senior breeders
(11-20 years and >20 years, 93 and 98.4\% respectively) (Table 5). All categories of $\mathrm{OBH}$ uniformly take individual performances of the stallion into account $(\mathrm{P}>0.05)$ (Table 5). The senior professionals use the performances of the ascendants, descendants or collaterals (siblings) as a source of information more than the occasional breeders $(\mathrm{P}<0.01)$ (Table 5). The performances of collaterals have less importance in the choice of stallions for both the professional and occasional breeders (Table 5). The professionals are less sensitive to the criterion of the stallion fees (Table 5) than the occasional breeders $(\mathrm{P}<0.001)$. The junior breeders are also more sensitive to the stallion fees $(\mathrm{P}<0.001)$, while the most experienced are prepared to stretch their budget according to the quality of the mating stallion. The majority of breeders giving weight to the location of the stallion is held in around $67 \%$ of professional and occasional breeders, preferring that it be held close to its breeding place and without any effect of experience on this variable $(\mathrm{P}>0.05)$. All breeders without distinction of experience or professionalization $(\mathrm{P}>0.05)$ are preferred stallions originating from private organizations to those originating from the public sector. Finally, among

Table 3 - Effect of the experience and degree of professionalization on the number of horses owned, the breed and the priority of breeding vs. racing (in \% of answers)

\begin{tabular}{|c|c|c|c|c|c|c|c|c|c|c|c|c|c|}
\hline \multirow{2}{*}{ Years of experience } & & & \multicolumn{5}{|c|}{ Professional breeders } & & \multicolumn{5}{|c|}{ Occasional breeders } \\
\hline & & & $1-5$ & $6-10$ & $11-20$ & $>20$ & Test & & $1-5$ & $6-10$ & $11-20$ & $>20$ & Test \\
\hline \multicolumn{14}{|l|}{ Variable } \\
\hline \multirow{4}{*}{ Number $^{\mathrm{c}}$} & $1-4$ & 62.7 & 60.0 & 66.7 & 68.7 & 56.8 & \multirow{4}{*}{ ns } & 74.3 & 66.2 & 73.2 & 78.9 & 79.4 & \multirow{4}{*}{ ns } \\
\hline & $5-9$ & 19.8 & 20.0 & 20.8 & 14.9 & 23.5 & & 12.0 & 16.2 & 11.0 & 9.9 & 11.1 & \\
\hline & $\geq 10$ & 17.5 & 20.0 & 12.5 & 16.4 & 19.7 & & 13.7 & 17.6 & 15.8 & 11.2 & 9.5 & \\
\hline & En & 20.9 & 60.0 & 33.4 & 20.9 & 14.8 & & 37.3 & 50.0 & 28.0 & 38.0 & 34.9 & \\
\hline \multirow{3}{*}{ Breed $^{a}$} & $\mathrm{Ar}$ & 23.2 & 40.0 & 20.8 & 34.3 & 13.6 & \multirow[t]{2}{*}{$* * *$} & 37.0 & 42.6 & 41.5 & 35.2 & 27.0 & \multirow[t]{2}{*}{$* *$} \\
\hline & Both & 55.9 & 0.0 & 45.8 & 44.8 & 71.6 & & 25.7 & 7.4 & 30.5 & 26.8 & 38.1 & \\
\hline & Racing & 2.8 & 40.0 & 12.5 & 0.0 & 0.0 & \multirow[b]{2}{*}{$* * *$} & 44.7 & 69.1 & 59.8 & 28.2 & 17.5 & \multirow[b]{2}{*}{$* * *$} \\
\hline Priority ${ }^{a}$ & Breeding-racing & 97.2 & 60.0 & 87.5 & 100.0 & 100.0 & & 55.3 & 30.9 & 40.2 & 71.8 & 82.5 & \\
\hline $\mathrm{n}$ & & 177 & 5 & 24 & 67 & 81 & & 284 & 68 & 82 & 71 & 63 & \\
\hline
\end{tabular}

ns $-\mathrm{P}>0.05, * * \mathrm{P}<0.01 ; * * * \mathrm{P}<0.001$.

Variables followed by the letters a and $\mathrm{c}$ are significantly different between total professionals and occasionals.

$(\mathrm{a}-\mathrm{P}<0.001 ; \mathrm{c}-\mathrm{P}<0.05)$; Number - number of horses owned; priority - priority given to the activity of breeding for racing or reproduction; Test - Chi ${ }^{2}$ or Fisher's exact test.

Table 4 - Effect of the experience and the degree of professionalization on the selection criteria for mares (in \% of answers)

\begin{tabular}{|c|c|c|c|c|c|c|c|c|c|c|c|c|}
\hline \multirow{2}{*}{ Years of experience } & & \multicolumn{5}{|c|}{ Professional breeders } & \multicolumn{6}{|c|}{ Occasionnal breeders } \\
\hline & & $1-5$ & $6-10$ & $11-20$ & $>20$ & Test & & $1-5$ & $6-10$ & $11-20$ & $>20$ & Test \\
\hline \multicolumn{13}{|l|}{ Selection criteria } \\
\hline WP & 74.0 & 80.0 & 70.8 & 80.6 & 69.1 & ns & 70.1 & 72.1 & 61.0 & 70.4 & 79.4 & ns \\
\hline PATH & 31.1 & 20.0 & 20.8 & 38.8 & 28.4 & ns & 23.9 & 25.0 & 21.9 & 22.5 & 27.0 & ns \\
\hline MCONF & 59.9 & 60.0 & 45.8 & 61.2 & 62.9 & ns & 65.5 & 72.1 & 64.6 & 57.7 & 68.2 & ns \\
\hline AFM & 37.3 & 40.0 & 23.9 & 44.4 & 50.0 & $*$ & 32.0 & 32.3 & 29.3 & 29.6 & 38.1 & ns \\
\hline GPM & 35.6 & 0.0 & 33.3 & 35.8 & 38.3 & ns & 29.9 & 29.4 & 30.5 & 29.6 & 30.2 & ns \\
\hline $\mathrm{n}$ & 177 & 5 & 24 & 67 & 81 & & 284 & 68 & 82 & 71 & 63 & \\
\hline
\end{tabular}

ns $-\mathrm{P}>0.05 ; * \mathrm{P}<0.05$

WP - weakest racing performance; PATH - occurrence of diseases; MCONF - the bad conformation of mares for the race; AFM - age at first mating of mares; GPM - use of good performing mares for mating; Test - $\mathrm{Chi}^{2}$ or Fisher's exact test. 
the professional breeders, a greater proportion of the senior breeders select calm stallions $(\mathrm{P}<0.05)$.

All OBH in the sample are aware of the existence of artificial mating (AM) for horses. However, 54\% decline to use it. The $46 \%$ who are in favor of AM are, in fact, members of the ANEPCRP. For them, resorting to artificial mating with fresh semen in collaboration with the National Center for Artificial Mating and Genetic Improvement (CNIAAG), which began in 2006, was an excellent initiative but has not grown enough. It is only used on the mares of the National Stud Farm.

Experience significantly influences the attitude of $\mathrm{OBH}$ to the problem of consanguinity $(\mathrm{P}<0.001)$. A large majority of senior $\mathrm{OBH}$ would prefer to avoid mating related animals (76.1 and $91.0 \%$ for $11-20$ years and $>20$ years categories, respectively), while a minority of junior breeders pay attention to this problem (17.8 and $37.7 \%$ of 1-5 years and 6-10 years categories, respectively) (Table 6). However, over $85 \%$ of junior breeders affirm the necessity to import horses from abroad $(\mathrm{P}<0.001)$ (Table 6). With regard to this importation, the senior breeders are in favor of separate racing for imported and local animals $(\mathrm{P}<0.001)$ (Table 6). More than $70 \%$ of senior $\mathrm{OBH}$ also envisage higher earnings to be ascribed to horses born and bred locally in order to promote local breeding (Table 6).

The owner-breeders of horses are unanimous in stating that they do not have enough assistance from the state. The financial support is adjudged to be too weak with food subsidies and birth bonuses that are not sufficient compared with the costs involved in producing a racehorse.

Regarding the analysis of the differences in the medians of the "ranking value" D among the junior and senior professionals (Table 7), for all OBH, the "ranking value" $\mathrm{D}$ is non-zero and positive. A significant difference between the junior and senior $\mathrm{OBH}$ is observed $(\mathrm{P}<0.001)$. The junior are prepared to lose $1,613 \$$ (median) to win first place against $658 \$$ for the senior breeders.

Table 5 - Effect of the experience and the degree of professionalization on the selection criteria of the stallions (in \% of answers)

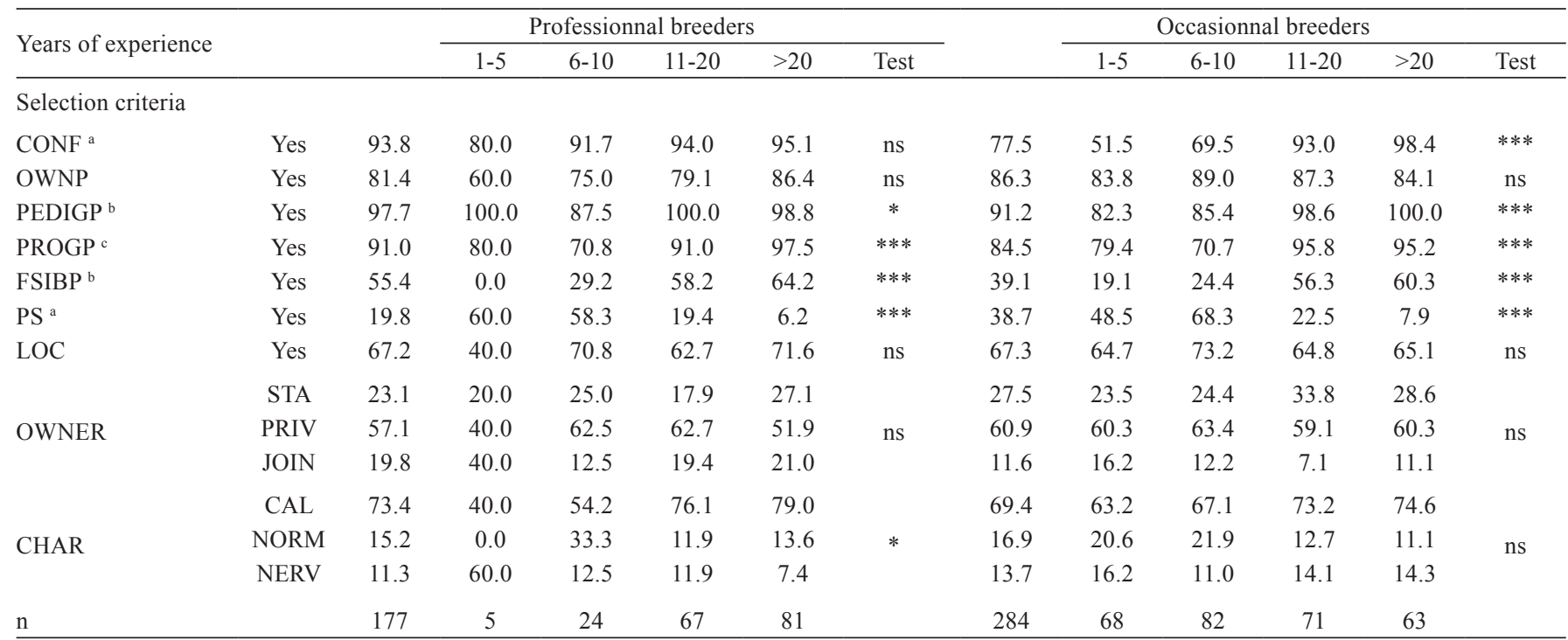

$\mathrm{ns}-\mathrm{P}>0.05, * \mathrm{P}<0.05$.

The criteria of selection stallions followed by the letters $\mathrm{a}, \mathrm{b}$ and $\mathrm{c}$ are significantly different between total professionals and occasionals $(\mathrm{a}-\mathrm{P}<0.001 ; \mathrm{b}-\mathrm{P}<0.01 ; \mathrm{c}-\mathrm{P}<0.05)$. $\mathrm{n}$ - number of OBH; CONF - conformation; OWNP - own performance; PEDIGP - pedigree performances; PROGP - progeny performances; HFSBP - half and full sister brother performances; PS - stallion fees; LOC - location of the stallion; OWNER - whether or not the breeding stallion belongs to the state or to a private owner (STA - state; PRIV - private; JOIN - as joined venture); CHAR - character of the stallion (CAL - calm; NORM - normal; NERV - nervous); Test - Chi ${ }^{2}$ or Fisher's exact test.

Table 6 - Measures recommended by owner-breeders according to experience

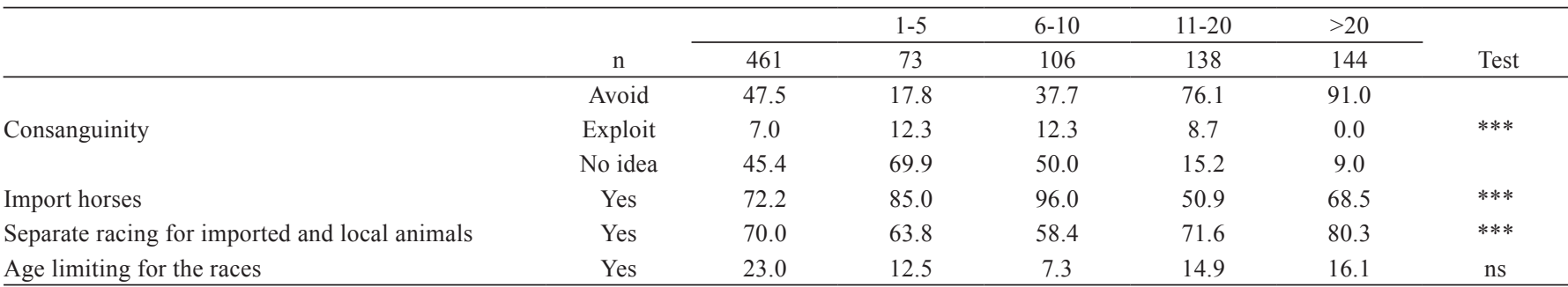

ns $-\mathrm{P}>0.05 ; * * * \mathrm{P}<0.001$.

Test - $\mathrm{Chi}^{2}$ or Fisher's exact test. 
Table 7 - Comparison of "ranking value" (D) between the young and old owners-breeders

\begin{tabular}{lccc}
\hline \multirow{2}{*}{ Experience } & $\mathrm{n}$ & \multicolumn{2}{c}{$\mathrm{D}(\$)$} \\
\cline { 3 - 4 } & & Median & P-value \\
\hline Junior $(1-10$ years $)$ & 28 & 1613 & $* * *$ \\
Senior $(\geq 11$ years $)$ & 32 & 658 & \\
$* * * \mathrm{P}<0.001$. & & &
\end{tabular}

\section{Discussion}

The number of $\mathrm{OBH}$ interviewed is high, representing $80 \%$ of the list of owners drawn up by the racing society. The poor representation of the Djelfa and Laghouat racetracks can be attributed to the fact that the Barb and Arabian-barb breeds take precedence at these venues to the detriment of Thoroughbreds and Arabian horses. The Zemmouri racecourse is the most represented because this is the racecourse with the greatest number of races. Considering the lack of bibliographical data, this survey sheds an important light on equine breeding and the selection of racehorses in Algeria.

The production of racehorses in Algeria brings together men from many different backgrounds. Women are absent from the sector as the breeding of large animals such as horses is traditionally a man-dominated activity in Algeria. There is a diversity of $\mathrm{OBH}$ in terms of their distribution across the Algerian territory, their choice of breeds, their socio-professional status and their breeding practices or even the mode of income-generation from breeding. Smallscale breeding is a characteristic that is widely shared. Many passionate $\mathrm{OBH}$ have invested a lot of time and work in their horse-related activities without necessarily enjoying any financial gain. The same results were found during a survey in 3 regions of France, with only $40 \%$ of the breeders reaching an objective of profitability or self-financing of horse breeding (Boyer et al., 2007). The predominance of experienced OBH might show that this activity is considered to be a long-term commitment by its participants. The higher number of occasional breeders in comparison with professional breeders could be partly explained by the suspension of the breeding and birth bonus by ONDEEC. When these bonuses were paid to breeders, they certainly helped to guarantee a minimum income for participants who were fully engaged in equine reproduction. For the last five years, these bonuses have not been paid regularly and have not increased in line with inflation. Hence, producers have reduced horse numbers and only occasionally use their mares for breeding. The relative homogeneity observed with regard to the criteria of choice of both professional and occasional breeders can be understood in this context: the change of direction or intensity of the activity has not fundamentally changed the practices and modes of decision-making.

Given the generally small scale of breeding, the selection possibilities for mares are limited in comparison with those of stallions. Poor reproduction performances (age at puberty, fertility and fecundity) limit the renewal of the generations. Only a third of the breeders withdraw mares from racing if they are still considered capable of racing. This practice contributes to an extension of the renewal time for generations and all the more so because the generation interval in sport horses is 10-12 years (Dubois and Ricard, 2007; Rognon and Verrier, 2008; Verrier et al., 2010). The selection criteria defined by the breeders for mares are less numerous than for the stallions, particularly concerning the information sources considered for selection (individual performances and those of relatives). The "selection criteria", as revealed during the preliminary survey and confirmed by the main survey, show that a positive selection of reproductive mares has not really been implemented. Because racing is prioritized, reproduction activity is like a second-best reserved for less performing females.

The larger possible distribution of semen causes strong selection pressure with regard to stallions, as observed in France with the Selle Francais breed (Dubois and Ricard, 2007). Due to the preference of Algerian breeders for natural mating, this selection pressure remains at the potential stage. The wide use of hand-breeding is in line with the overall preference for calm stallions, especially shown here for senior breeders. The negative attitude of breeders towards AI and other modern reproduction techniques could be explained by the lack of investment of the authorities concerned in the education and information of the $\mathrm{OBH}$.

The importance attributed by breeders to the criterion of conformation refers mainly to the conformation of limbs as these have a particular importance in the discipline of racing (Pieszka et al., 2011). The information sources used by breeders combine individual performances and those of relatives. With regard to selection behavior explained here in relation to males and females, it is understandable that the selection of males is largely based on their paternal and sometimes maternal origins. Some owners also choose stallions and breeding lines that have already proven their worth by using the performances of their descendants. The latter practice, which is more common among the senior breeders, is the sign of greater expertise and a more active attitude towards genetic improvement. Nevertheless, in the absence of an index of genetic value, the choice that is made is not a well-informed one. The fact that breeders 
take these information sources into account nonetheless confirms their ability to take on board a national tool based on an indexing of the performance of racehorses. It is to be noted that such an index, which is based on race results, is sufficiently accurate when individual performances have been recorded and the performances of a large number of descendants are known (Verrier, 2011). Therefore, a wide participation of the breeders is necessary and is based on their acceptance of the suggested tool.

Consanguinity, caused by the mating of relatives, reduces the genetic variability of horse populations and has a negative effect on their morphology (Klemetsdal, 1998), the quality and fertility of sperm (Weitkamp et al., 1982; Colenbrander et al., 2003) and the fertility of mares (Klemetsdal and Johnson, 1989). In association with the analysis by the authors of documents of official pedigree (unpublished), the present survey points to a latent problem of consanguinity among the numbers of Algerian Thoroughbreds and Arabian horses. The most experienced $\mathrm{OBH}$ are aware of these problems. However, they cannot avoid consanguinity given the lack of choice for breeding animals. Also, despite this acknowledgement of the negative consequences of consanguinity, breeders prefer to remain with their own breeding lines or they only accept animals that they already know, which further limits the choice of stallions.

Owner-breeders of horses hiring the services of privately held stallions justify their choice by the better racing performances of the latter. It appeared from discussions that stallions are in fact often imported by private organizations that are approved by the National Stud Farm for breeding. Public stallions being exclusively locally bred ones, "privately held stallions" might often mean "imported stallions". It should be noted that junior breeders are more open to the use of stallions originating from abroad. Such usage should be encouraged as part of breeding policy. Indeed, resorting to imported genetics will be necessary to enlarge the genetic basis upon which any expected progress must be built. Although the interviewees did not address this topic, the owning of such high-quality imported stallions might be linked to particular influence in the equine sector. If such an influence is confirmed, it could be of importance for the smooth implementation of a national breeding program.

As dealt with here, the "ranking value" is indicative of the mode of decision-making of the breeders, pointing to the importance attributed to ranking for its own sake rather than the amount won. In this study, the junior OBH attribute more importance to rankings than the senior. The junior professionals seem to be searching for recognition for their horses. This may be linked to their activity of selling horses that they have raced. They consider themselves as ownerbreeders and horse traders in their own right. As first-place winning horses will be sold at higher price, the value they attribute to victory may be understood as foregoing present earnings for later gains. The activity of buying-racingreselling is indeed a more important source of income for them than earnings from races in the strictest sense. In contrast with senior professional breeders, who can afford to maintain an activity that does not make a lot of money as long as it is their passion, a young breeder who sets up in the industry can only develop such a demanding activity if his profitability is guaranteed. The sale of victorious horses can therefore provide the means for this profitability.

Earnings and rankings are two performance indicators that are similar in terms of potential. At the national level, the choice of one or the other characteristic to estimate the breeding value of the animals will depend on technical factors such as heritability (Chico, 1994; Belhajyahia et al., 2003; Svobodova et al., 2005; Bakhtiari and Kashan, 2009). Provided that the rankings are statistically normalized and transformed, they enable a hierarchical classification of all the horses, even if they have not directly met. In fact, the level of an event is measured by the rankings of horses in the event, obtained from the other events they have participated in (involving iterated estimation). Furthermore, the transformed rankings show the advantage of not being expressed in monetary terms. Indeed, as a monetary value, the earnings are subject to larger economic influence, such as inflation and exchange rates where genetic importation is envisaged, for which it is difficult to correct the performances of the stallions. Hence, ranking presents a major advantage for international comparison as it is the same in all countries (Tavernier, 1990). The current internationalization of racing contributes to improving the accuracy of estimates based on this criterion. On the contrary, the use of earnings as criterion reduces the level of the race (performance test) to differences in its endowment, without taking account of the differences in quality between the horses involved or taking it as a given that the better paid races are those that attract the best horses. These endowments will depend on national policy, which vary from one country to another. However, earnings are judged useful because they are willingly used by breeders to estimate the level of performance of the horses (Langlois and Blouin, 2004). They would therefore be a major objective of the breeders at the same time as a criterion of comparison at a national level. The question of adoption of the index by its users is therefore central to the choice between ranking and earnings as an assessment criterion. The value attributed to ranking in relation to earnings as shown in this study 
indicates that the adoption by Algerian breeders of a selection index based on ranking is possible. Finally, it must be noted that the recording of the ranks from the first to last for all the races held in Algeria is currently practiced by SCHPM. This recording represents a valuable opportunity, making it possible to assess stallions with great accuracy by taking account also of performances outside five first ranks.

\section{Conclusions}

The lack of organization of breeders as well as the importance of the horse buy-resell activity (following a shortterm logic) are both opposed to the basic logic of selective breeding. Nonetheless, a request for better organization, information and supervision of horse breeding was expressed here. Likewise, OBH showed an interest in selective breeding. Accordingly, it is urgent to instill an economic and professional logic into the sector. This professionalization would allow for an efficient genetic improvement at national level. Given the lack of a strong breeders organization, public authorities should play a major coordinating role. The practice of consanguinity has eroded the genetic diversity. Thus, the latter should be rebuilt through the import of highvalue horses. The growing propensity of breeders to seek stallions abroad should be encouraged and controlled. The authorities should also promote the early withdrawal of the best horses from racing for use in mating.

\section{References}

Bakhtiari, J. and Kashan, N. E. J. 2009. Estimation of genetic parameters of racing performance in Iranian Thoroughbred horses. Livestock Science 120:151-157.

Belhajyahia, T.; Blouin, C.; Langlois, B. and Harzalla, H. 2003. Breeding evaluation of arab horses from their racing results in Tunisia by a BLUP with an animal model approach. Animal Research 52:481-488.

Benabdelmoumene, M. 2003. Races équines (chevaux, mulets, ânes). p.62-67. In: Recueil des Communications «Biodiversité Importante pour l'Agriculture».

Boyer, S.; Couzy, C.; Morhain, B.; Veron, J. and Pavie, J. 2007. Les éleveurs équins en recherche de rentabilité. p.105-117. In: 33ème Journée de Recherche Equine. Les Haras Nationaux, Paris, France.

Chico, M. D. 1994. Genetic-analysis of thoroughbred racing performance in Spain. Annales de Zootechnie 43:393-397.

Colenbrander, B.; Gadella, B. M. and Stout, T. A. E. 2003. The predictive value semen analysis in the evaluation of stallion fertility. Reproduction in Domestic Animals 38:5-11.
Dubois, C. and Ricard, A. 2007. Efficiency of past selection of the French sport horse: Selle Français breed and suggestions for the future. Livestock Science 112:161-171.

FAOSTAT. Statistical database 2010. Available at: <http://faostat.fao. org/site/573/default.aspx\#ancor> Accessed on: Jan. 3, 2012.

Goebel, G. 1995. Fortschritte bei der verhaltensmedizinischen Diagnostik und Behandlung quälender chronischer Ohrgeräusche. Otorhinolaryngol Nova 5:78-89.

Gold, M.; Siegel, J. and Russell, L. 1996. Cost-effectiveness in health and medicine. Oxford University Press, New York.

Happich, M.; Moock, J. and Von Lengerke, T. 2009. Health state valuation methods and reference points: The case of Tinnitus. Value in Heath 12:88-95.

Kadri, A. 2006. Le cheval barbe, cheval du Nord de l'Afrique, son rôle en Algérie. Revue Organisation Mondiale 1:9-45.

Klemetsdal, G. 1998. The effect of inbreeding on racing performance in Norwegian cold blooded trotters. Genetics Selection Evolution $30: 351-366$

Klemetsdal, G. and Johnson, M. 1989. Effect of inbreeding on fertility in Norwegian trotter. Livestock Production Science 21:63-72.

Langlois, B. and Blouin, C. 2004. Practical efficiency of breeding value estimations based on annual earnings of horses for jumping, trotting, and galloping races in France. Livestock Production Science 87:99-107.

MADR - Ministry of Agriculture and Rural Development. 2009. Balance sheet of agricultural statistics 2008. Sub-Department of Statistics, Ministry of Agriculture and Rural Development, Algeria. p.25.

OIE - Office International des Epizooties (Organisation Mondiale de la Santé Animale). 2010. Santé Animale Mondiale en 2009. OIE, Paris. p.619.

Pieszka, M.; Luszcynski, L. and Baranowska, A. 2011. Frequency of limb injuries between Thoroughbred and Arabian horses. Iranian Journal of Applied Animal Science 1:69-71.

Rognon, X. and Verrier, E. 2008. Suivi de gestion de la variabilité génétique des populations équines. p.69-87. In: L'amélioration génétique des équidés. Haras Nationaux, Paris, France.

Svobodova, S.; Blouin, C. and Langlois, B. 2005. Estimation of genetic parameters of Thoroughbred racing performance in the Czech Republic. Animal Research 54:499-509.

Tavernier, A. 1990. Estimation of breeding value of jumping horses from their ranks. Livestock Production Science 26:277-290.

Verrier, E. 2011. L'amélioration génétique: une activité humaine organisée, au service de l'adaptation des populations animales. p.85-92. In: 37ème Journée de la Recherche Equine. Les Haras Nationaux, Paris, France.

Verrier, E.; Leroy, G.; Blouin, C.; Mériaux, J. C.; Rognon, X. and Hospital, F. 2010. Estimating the effective size of farm animals populations from pedigree or molecular data: a case study on two French draught horse breeds. In: Proceedings of the 9th World Congress on Genetics Applied to Livestock Production, Leipzig, Germany. Communication 0198 (cd-rom).

Weitkamp, L. R.; MacCluer, J. W.; Guttormsen, S.; McKnight, J.; Wert, N. and Witmer, J. 1982. Genetics of Standardberd stallion reproductive performance. Journal of Reproduction and Fertility. Supplement 32:135-142. 